\title{
Reciprocity, Transitivity, and the Mysterious Three-Cycle*
}

\author{
PER BLOCK ${ }^{\dagger}$ \\ ETH Zürich \\ per.block@gess.ethz.ch
}

\begin{abstract}
Reciprocity and transitivity are the two most important structural mechanisms underlying friendship network evolution. While on their own they are understood in great detail, the relation between them is rarely studied systematically. Are friendships outside of social groups more or less likely to be reciprocated than friendships embedded in a group? Using a theoretical framework that focusses on the situations in which friends interact and the social structures that stabilise one-sided friendships, I propose that the tendency towards reciprocation of friendships within transitive groups is usually lower than outside of transitive groups. In a meta-analysis of two datasets including 30 friendship networks using stochastic actor-oriented models (SAOMs), the interaction between reciprocity and transitivity is analysed. Supporting the theoretical reasoning, the interaction is consistently negative. Second, the tendency against forming three-cycles in friendship networks, which was consistently found in previous studies, is shown to be spurious and a result of neglecting to control for the tendency against reciprocation in transitive groups. The tendency against three-cycles is commonly seen as an indicator that unreciprocated friendships indicate local hierarchy differences between individuals; this proposition has to be re-evaluated in light of the findings
\end{abstract}

${ }^{*}$ Cite as: Block, P. (2015). Reciprocity, transitivity, and the mysterious three-cycle. Social Networks, 40, 163-173.

${ }^{\dagger}$ I would like to thank the members of the statistical network modelling group at Nuffield College, Oxford, the social networks Groups at the University of Groningen, and at ETH Zürich for their helpful comments and suggestions at different stages of the manuscript preparation. Especially, I would like to thank Tom Snijders. 
of this study. Future studies that analyse the evolution of friendship networks should consider modelling reciprocation in transitive triplets and potentially omit modelling three-cycles.

\section{Introduction}

Interpersonal friendships are an important part of many people's lives and have been researched by social scientists for more than a century (Heidler et al., 2014). What constitutes a friendship in academic research? Although friendship is not a well defined concept (Fischer, 1982; van de Bunt et al., 1999), the majority of friendship definitions have two aspects in common. First, friends tend to voluntarily spend time together in social situations. This is put forward for example by Fischer (1982), who finds in an inductive study that "[friendship] ties tended primarily to be relations of sociability, ones in which people visited, went out together, discussed shared pastimes, participated in some organization together, and so on." (p. 306). Carley and Krackhardt (1996) refer to friendship as an interaction-based relationship. In "Friendship as a social process", Lazarsfeld and Merton (1954) propose that friendship develops and is maintained through voluntary and rewarding contact with another individual. Evidently, having a forum for interaction is a condition for friendship.

Second, and this might seem fairly obvious, the interactions are rewarding, i.e. people like spending time with their friends; and more generally, people like their friends. Thus, friendship has two dimensions - interaction and evaluating these interactions positively. Naturally, these two are highly interdependent. For people to evaluate interaction positively, it has to take place; and people seek to interact with others they like. While this distinction might seem trivial and obvious, it is very relevant. Most theories that explain the evolution of friendships and the emergence of particular patterns focus on either one of these processes - what makes people likely to interact? and what makes people likely to evaluate interactions and people positively? This article, which treats the interrelation between two prominent friendship evolution mechanisms, will focus on both of these two distinct dimensions.

A substantial part of the evolution of friendships over time is driven by endogenous network mechanisms. An actual or potential friendship between two individuals is embedded within a friendship network that guides the creation of new and the maintenance of existing friendship ties. This means that the current state of a friendship network depends on its previous state, and certain changes of friendship configurations between two or more individuals are more likely than others. 
Paramount among the endogenous mechanisms, as suggested by a long tradition of network research are the mutuality of friendships and that friends tend to form groups (Rivera et al., 2010). Indeed, statistical modelling of friendship dynamics shows that the two most important endogenous, or relational, network mechanisms are reciprocity and clustering (Snijders et al., 2010; Veenstra et al., 2013). Degree dynamics, which play an important role in other types of social networks, such as sexual contacts (Liljeros et al., 2001) or citation networks reflecting the "Matthew effect" (Merton, 1968), are less important in friendship networks, as the continuing investment of time and resources in friendships inhibits actors from acquiring a very high degree (Rivera et al., 2010). Hence, this article focusses on reciprocity and clustering in friendship networks.

\section{$1.1 \quad$ Reciprocity}

In the context of friendship, reciprocity means responding to other peoples friendly gestures in kind (Schaefer et al., 2010). In network terms, reciprocation describes the increased likelihood of individuals to send ties to those from whom they receive a tie. This dyadic relational mechanism is intuitively plausible and, for strong friendship ties, often understood as implicit in the definition of friendship (Newcomb, 1956). Some research defines friendship ties a priori as mutual (e.g. Krackhardt, 1992) and, therefore, models friendships as undirected. In statistical analysis of friendship digraphs, reciprocation is often the most powerful predictor of the existence of a tie.

A common explanation underlying reciprocation in friendships is based on Social Exchange Theory (Emerson, 1976; Rusbult and Buunk, 1993). It suggests that people invest in those they perceive as friends and expect rewards from these investments. Both costs and returns can take the form of time committed, emotional support, advice, presents, and so on. In case individuals find the balance between costs and returns unsatisfying or they have a better alternative, the friendship may be broken. From this perspective, friendship needs mutuality in investment to be evaluated positively and one can see why friendships tend to be reciprocated. However, based on Social Exchange Theory, it is not strictly necessary that friendships are reciprocated. Rather the balance of given and received friendly behaviour needs to be satisfying for an individual. This is of course more likely if both parties involved in a friendship perceive the other as a friend. However, a one-sided friendship can also be stable if the sole nominator does not feel an imbalance between giving and taking in the relationship.

Other intuitions behind reciprocity propose that similarity breeds connection (called homophily, Lazarsfeld and Merton, 1954). As similarity is a 
characteristic of a pair of individuals, it breeds connection in both directions. Similarity can include any type of measurable and latent attributes and attitudes. Further, Homans (1950) states that time spent together makes people more likely to become friends. Time spent together is symmetric between two individuals, therefore leads to reciprocated friendships.

\subsection{Clustering}

The other persistent relational network mechanism underlying friendship dynamics is clustering. Clustering describes the tendency of people to form ties within social groups, where one's friends are connected to each other, too. This means that indirect connections between individuals - i.e. two unconnected actors that are tied to the same third party, or that are connected by a two-path - tend to become direct connections over time. In directed friendship networks, closure is generally represented by a transitive triplet (see Snijders et al., 2010). A transitive triplet between the three actors $i, j$ and $h$, is defined as a tie being present from $i$ to $j$, from $j$ to $h$, and a tie being present from $i$ to $h$ (Figure 1a). There are many theoretical rationales that explain clustering/transitive closure in friendship networks.

One of the first approaches was given by Simmel (1950). He suggested that joint membership in a group leads to clustering in social networks. Further, if two people have a common acquaintance, they are more likely to meet and get to know each other (e.g. Granovetter, 1973). In other words, time constraints in individuals' social contacts lead to clustering in a network. Both of these very similar explanations propose that having a common friend makes it more likely that people meet and spend time together and thus become friends. These explanations therefore operate on an increased likelihood to interact between people with common friends.

Complementary to this, Balance Theory (Heider, 1946; Newcomb, 1961) proposes that people tend to evaluate the friends of their friends more positively. It suggests that people seek balanced relationships in their lives and a triad is only balanced if the number of positive ties is odd. Therefore, open triads tend to either close, or loose a positive tie. In other words, if my friend likes somebody I do not like, I will feel psychological discomfort and either change my opinion about the friend-of-friend in a positive way or break my relation to the friend.

Further mechanisms that lead to clustering are that an indirect connection can ease access to information about the potential interaction partner, reducing the potentially involved risk of engaging in interaction (Granovetter, 1985) and homophily of a group of people leading to network closure (e.g. Goodreau et al., 2009). 

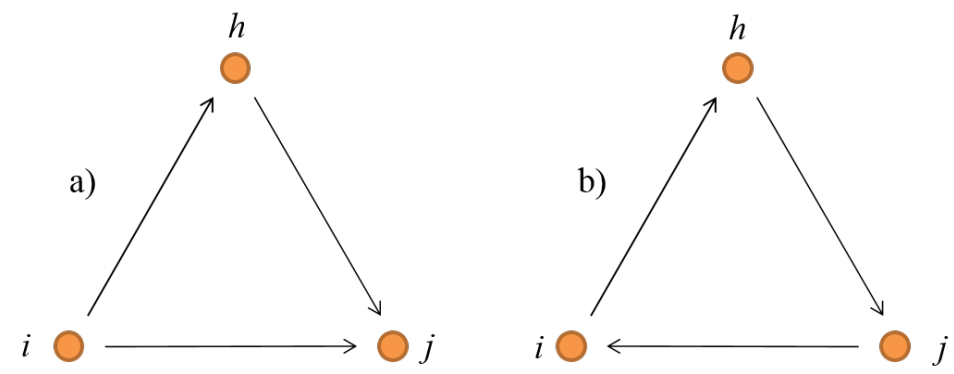

Figure 1: a) Transitive Triplet and b) Three-Cycle

\subsection{The Mysterious Three-Cycle}

Since the increasing popularity of Stochastic Actor-Oriented Models (SAOMs), another triadic configuration that guides network evolution has received growing attention, and is by now among the frequently used relational mechanisms modelled in analyses of friendship networks using SAOMs: the threecycle. In a triad of actors $i, j$, and $h$, it describes the configuration where a tie from $i$ to $j$, a tie from $j$ to $h$, and a tie from $h$ to $i$ is present (Figure 1b). This configuration is similar to the transitive triplet, except that the direction of the tie from $i$ to $h$ is reversed. With surprising consistency, it has been found in many analyses of friendship networks that the effect that models whether actors choose to be in such a cyclic configuration is negative and both, highly significant and of substantial size (in recent studies for example Cheadle et al., 2013; Ellwardt et al., 2012; Giletta et al., 2012; Preciado et al., 2012; Snijders et al., 2010; Steglich et al., 2012; van Workum et al., 2013; Veenstra et al., 2013).

The canonical explanation for the negative three-cycle effect in friendship networks refers to a theoretical model proposed by Davis and Leinhardt (1970), and its further elaboration (Davis, 1970). This model states that the directionality of an unreciprocated tie indicates a hierarchy difference, where the recipient of a tie occupies a higher position than the sender. Presence of a cyclic network configuration indicates a cyclic hierarchy, which is very unlikely as hierarchy is generally transitive. Following this model, the tendency against three-cycles in friendship networks is commonly interpreted as an indication for the presence of local hierarchies in friendship networks. This implies that the observed preference relations (friendships) are, when unreciprocated, similar to dominance relations. 


\subsection{The Relation Between Reciprocity and Clustering}

While reciprocity and clustering in the evolution of friendship networks has been thoroughly analysed, little attention has been paid to the interplay of these two mechanisms. One reason why the interaction between transitivity and reciprocity has received little attention might be that in the majority of theoretical work on triadic closure, friendships are understood as mutual, therefore rendering the question moot. However, given that much empirical analysis of friendship dynamics focuses on directed friendship ties, an important question that arises is whether reciprocation is more or less likely within social groups or transitive triads, as opposed to non-embedded friendships. Since statistical methods for studying network dynamics are widely available by now (Snijders, 2011), studying the interaction between reciprocity and transitivity is facilitated from an empirical point of view. However, the only statistical network study that models such an interaction between these effects known to the author is Igarashi (2012). This study employed static ERGMs and did not discuss the interaction theoretically.

Some work on reciprocation within triads is done on so-called Simmelian ties (following Krackhardt, 1992). Simmelian ties are reciprocated ties where both partners are also mutually strongly connected to a common third party. In a digraph, this is represented by a complete triad with all six possible ties being present. This means that Simmelian ties do not per se deal with reciprocation in triads, only with the special case where all ties in a triad are reciprocated. Further, this line of work is mainly concerned with the consequences of this type of ties (Krackhardt, 1999; Tortoriello and Krackhardt, 2010), or their persistence (Krackhardt, 1998). The emergence of Simmelian ties is not in the focus of this research, especially not the relationship of reciprocation within, compared to outside of transitive triads.

Therefore, from a theoretical and empirical point of view, the question remains whether reciprocity is equally likely within, compared to outside of transitive triplets, and how the two mechanisms are interrelated. This research question also relates to the review article on network dynamics by Rivera et al. (2010), who point out that there is a lack of research on how different network mechanisms are related.

\section{Theory and Hypothesis}

\subsection{Reciprocity in Transitive Triplets}

How do reciprocity and clustering interact? Does embeddedness in a social group stabilise reciprocated friendships - comparing Figure 2c) to $2 \mathrm{~d}$ ) - and 


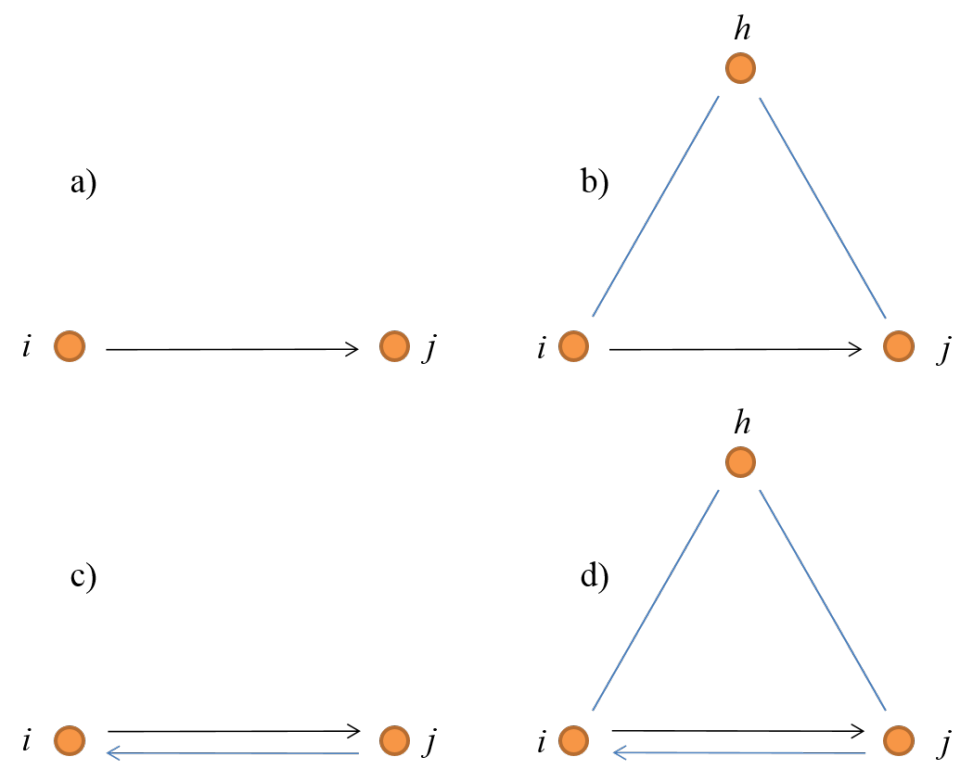

Figure 2: a) One-sided, b) Embedded, c) Reciprocated, and

d) Embedded and Reciprocated tie from the perspective of actor $i$.

one-sided friendship equally - comparing Figure 2a) to 2b)? Employing explanations that refer to both the likelihood of interaction between two people and the positive evaluation of interaction, I argue in the following paragraphs that the mechanisms that lead to a stabilisation of one-sided friendships that are transitively embedded, are less relevant for reciprocated friendships that are embedded in a transitive triplet; i.e. the interaction is negative.

First, I employ the perspective that focusses on the likelihood of interaction between two individuals. I argue that only one-sided, not embedded friendships (Figure 2a) do not have a forum for interaction, and thus are especially unstable compared to the other three configurations in Figure 2.

Reciprocated friends are likely to seek regular contact with one another, as both consider the other a friend and friends want to spend time together. They can create situations in which they interact that include either just the two of them or take place within a group context. Thus, they fulfil the necessary condition that friends need to interact with one another, regardless of whether this reciprocated friendship is transitively embedded or not.

For one-sided friendships, the matter is different. Being embedded in a social group provides a forum for social interaction between the sender and the recipient of a one-sided friendship. A common friend makes regular faceto-face interaction between two people more likely. Contrarily, the sender and recipient of a one-sided, not embedded friendship will have no forum 
to interact with one another. They do not spend time together in dyadic situations the same way that reciprocated friends do. This is because the recipient of the friendship will have no interest in meeting in a dyad, as he does not consider the sender a friend. They also do not spend time in a group together, as they do not have common friends. Thus, of the four configurations in Figure 2, only 2a) does not provide a forum for interaction between $i$ and $j$.

For one-sided friendships, a social group provides the primary and only forum for interaction between the two involved individuals, thus, it is crucial for the existence of the tie. Between reciprocated friends, on the other hand, the social group is just an additional opportunity to interact. If their joint friendships deteriorate, they can compensate the loss of time spent jointly in a group by interacting in dyadic situations, which is not possible for onesided friendships. Focussing on the likelihood of individuals to interact, it becomes clear why transitivity is more important for one-sided than twosided friendships.

I follow a similar line of argument when focussing on the positive evaluation of a relationship. According to Social Exchange Theory, friendships in which one person perceives an imbalance between giving and taking are unlikely to be maintained or form in the first place. In reciprocated friendships, such an imbalance is unlikely. Both value the other and perceive them as a friend and are likely to reciprocate the friendly gestures of the other. This exchange should be independent of whether the friendship is embedded in a group or not, i.e. for reciprocated friends, embedding in a social group has little influence on whether an individual is likely to be satisfied with the rewards he gains from the friendship.

In an unreciprocated friendship, this is different. Here, the recipient of the one-sided friendship needs to behave positively to the sender so that he does not break the friendship, because it gives too little rewards. Why should the recipient be nice to the sender of the one-sided friendship? Luckily, people behave in a friendly and positive way not exclusively to those they call friends. Other reasons for friendly behaviour are that it makes everyday interactions with others more pleasant and serves to be "on good terms" with somebody (van de Bunt et al., 1999). This kind of friendly behaviour is promoted by having common friends. People act friendly to their friends' friends to increase the joy of group-based interactions. A lack of friendly behaviour to others when spending time in a group is likely to result in tension. Further, balance theory gives a good rationale why people are positive to their friendsof-friends. A negative attitude will lead to cognitive dissonance that the involved individuals will try to resolve.

On the other hand, this sort of friendly behaviour on the part of the 
recipient is less likely where the one-sided friendship is not embedded in a social group. Not being nice outside of a group does not have the adverse consequences it does within a group of creating tension and psychological discomfort due to imbalanced relationships. Therefore, for the recipient of a one-sided friendship the motivation to be friendly to the sender is much lower if the friendship is not embedded in a group.

Additionally, outside of a social group in an unreciprocated friendship it is likely that its one-sidedness becomes very obvious and painful to the sender of the friendship. His advances towards joint activities and kind gestures are unlikely to be honoured and reciprocated, respectively. Consequentially, these friendships are likely to be broken quickly or not even to form in the first place. Within a social group, the one-sidedness of a friendship will not be as apparent.

In sum, being part of a common group stabilises a one-sided friendship, as the recipient will behave in a positive way towards the sender, which makes the friendship rewarding for the latter. For mutual friends, behaving positive towards one another is mostly independent of whether the tie is embedded in a group or not. Therefore, from a perspective that focusses on the rewards to a friendship, I argue that the positive effects of transitivity on friendship operate mainly on one-sided friendships.

Summarising these two lines of argument, I propose that unreciprocated friendships are more likely to exist within social groups, compared to asymmetric friendships outside of social groups. These stabilising effects of group embeddedness are not essential in reciprocated friendships. The effect of transitivity is smaller for reciprocated friendship than for one-sided friendships. Thus, in an empirical analysis of network dynamics, the tendency towards reciprocation should be lower within groups than outside of groups. The first hypothesis of this paper is:

Hypothesis 1: The tendency towards reciprocation within transitive triplets is lower than outside of transitive triplets.

The triadic substructures that combine the transitive triplet with reciprocation are displayed in Figure 3. These substructures depict every possible triad that contains clustering and reciprocity and are, therefore, directly related to the hypothesis. Controlling for the tendency towards transitivity and reciprocity, according to hypothesis 1 there should be a tendency against forming and maintaining these substructures. 


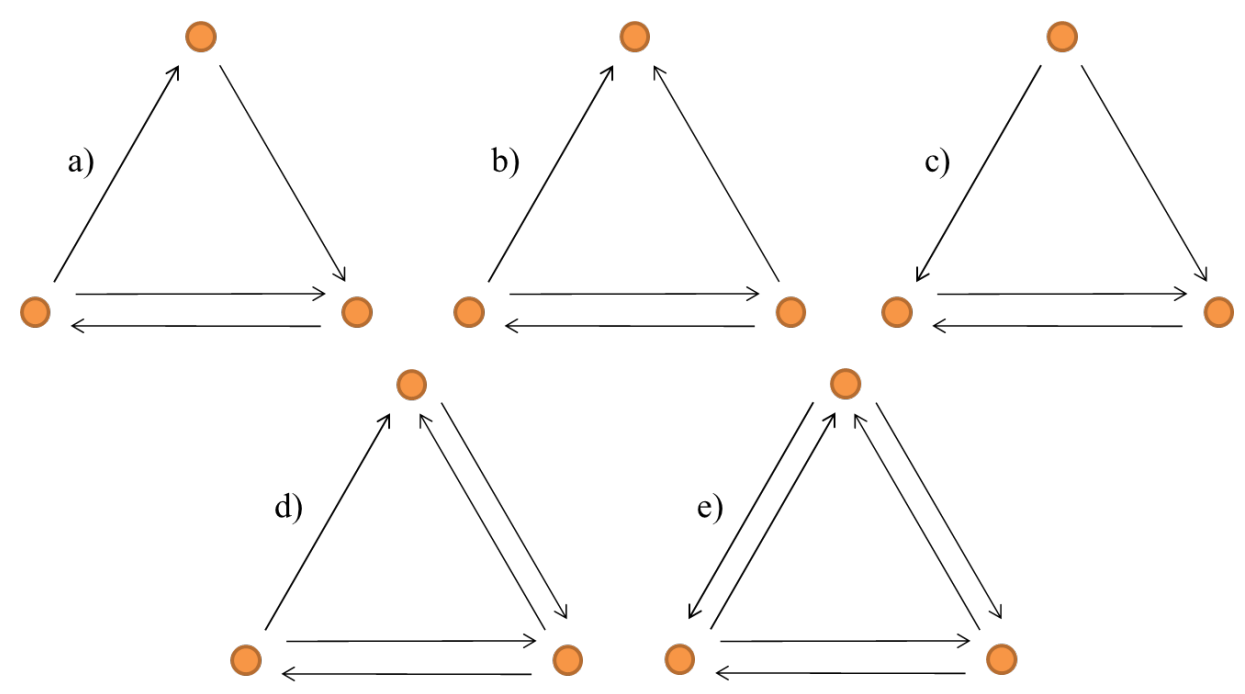

Figure 3: Triadic configurations with four or more ties

\subsection{The Spurious Three-Cycle}

Using Figure 3, I now relate the concept of reciprocation in triads to the threecycle. It can be seen that three of the triadic structures in Figure 3 (a, d, and e) contain a three-cycle. Following hypothesis 1, in an empirical analysis the tendency towards reciprocation within triads should be negative. Thus, there should be a tendency against forming any of the configurations in Figure 3. If, however, this tendency is not modelled, but instead the tendency towards forming three-cycles, the parameter that models the formation of three-cycles should pick up the effect of the omitted network structures. This means that, if hypothesis 1 is confirmed, the found tendency against forming three-cycles could (at least partly) represent the tendency against reciprocation in triads. In other words, the observed negative tendency against forming three-cycles may be spurious. If this is the case, it casts serious doubts on the common interpretation that the tendency against forming three-cycles is indicative of the existence of local hierarchy in friendships. This leads to the second hypothesis:

Hypothesis 2: When controlling for the tendency towards reciprocation in transitive triplets in an analysis of friendship network evolution, the tendency against forming three-cycles decreases or disappears compared to analyses in which the tendency towards reciprocation in triads is not modelled. 


\section{Data}

Two independent datasets are used to test the proposed hypotheses. The first dataset, which I will refer to as the Dutch data, is taken from the Dutch Social Behavior Study (Houtzager and Baerveldt, 1999). In the mid-1990s, this two wave network dataset was collected in a total of 23 high-schools, of which 19 took part in both waves. Data was collected on students in their 3rd year of high-school at the intermediate educational level (most aged between 15 and 17) with classroom sizes varying from 31 to 91, amounting to a total of 990 pupils. Data collection was conducted by in-classroom questionnaires, where students gave information on some demographic and behavioural characteristics, of which only sex is used in the current study. Further, a number of social network items were measured that jointly were coded into a binary friendship network for each classroom. These refer to support given and received by another member of the network. Details of how the network was created can be found in Snijders and Baerveldt (2003). The dataset has been used in a number of network studies and is regarded as a thorough and high quality study of multiple comparable networks (e.g. Snijders and Baerveldt, 2003; Baerveldt et al., 2004). Further, it is publicly available on the Siena website ${ }^{1}$.

The second dataset, called the British data in this article, was collected as part of the A Stop Smoking In Schools Trial (ASSIST). Between 2002 and 2004, students of 11 secondary schools in England and Wales were administered questionnaires annually. In the first wave, students were in their second year of secondary school; throughout the study, the pupils were mostly between the ages of 12 and 16. Cohort sizes varied from 80 to 236 pupils, with a total of 1716 adolescents taking part in the study. Participants reported demographic characteristics, as well as substance use patterns. In this analysis only the sex of the adolescents is used. Further, they nominated up to six friends within their cohort, from which the friendship networks were created for the three time-points. Details of the context in which the data was collected can be found in Steglich et al. (2012).

To ensure that support of the hypotheses is not due to specific characteristics of either dataset, they represent different contexts with regard to time, participant age, and location. Further the friendship networks were obtained using disparate methodology. The main difference in the network characteristics between the two datasets is the average number of friends, which can be attributed to the way the networks were created. While in the Dutch data the friendship networks were created from a set of items relating

\footnotetext{
${ }^{1}$ http://www.stats.ox.ac.uk/ snijders/siena/CB_data.zip. Last accessed 07.10.2014.
} 
to support between students, in the UK data students were simply asked to nominate up to six friends. Descriptive statistics of all analysed networks can be found in Tables A.1 and A.2 in the Appendix. They provide an overview of the different classes with regards to network size, density, composition, and stability between the different waves of data. Further, some description is given on average characteristics of friendships between students in form of the proportion of ties that are between same sex peers, that are reciprocated and that are embedded in transitive triplets.

\section{Method}

\subsection{SAOM/Siena Models}

The different networks are analysed using Stochastic Actor Oriented Models (SAOM), (Snijders, 2001, 2005; Snijders et al., 2010), implemented in the program SIENA (Ripley et al., 2013). SAOMs are by now widely employed in the longitudinal analysis of the evolution of social networks ${ }^{2}$. SAOMs describe patterns of changes in a network measured at different time-points. While the network is observed at discrete times, change in the network is assumed to take place in continuous time, where only one tie can change at a time. These changes only depend on the current state of the network, i.e. actors in the networks are assumed to neither act strategically or dependent on the earlier past. All tie changes (creation, maintenance, and dissolution of a tie) are modelled from the perspective of the actor that is sending the tie.

Making a tie change involves a two-step process: First, the actor that will make a tie change is chosen, and second, it decides which tie to change. Among all possible tie changes, the actor decides which one results in the most attractive network from its perspective, and, with some random error, executes this change. Which network state is most attractive to the actor depends on so called effects. These indicate to whom an actor prefers to send ties in relation to both, their structural position and their attributes. For a more detailed introduction to SAOMs, including details about estimation procedures, I refer to Snijders et al. (2010). The effects included in the analyses including a brief description are listed in Table 1.

The detailed model specification for the two data-sets differs slightly regarding the degree-related effects Indegree Activity, Outdegree Activity, Indegree Popularity and Outdegree Popularity. The models were chosen according

\footnotetext{
${ }^{2}$ http://www.stats.ox.ac.uk/ snijders/siena/siena_applications.htm. Last accessed 07.10.2014.
} 
to which provided the best fit (see Section 4.3) for either data-set. As the networks differ in their size and average degree, a different set of effects that model degree dynamics need to be employed in each model. All parameters in the analyses are estimated using Method of Moments. Estimations were repeated until all convergence ratios were below 0.1 .

\subsubsection{Hypotheses Testing}

Two effects are needed to test the proposed hypotheses. These are the Three Cycle effect for hypothesis 2 effect and the Transitive Reciprocated Triplets effect for both hypotheses. The latter effect was not discussed in the literature so far and was implemented in RSiena especially to model the tendency towards reciprocation in transitive triplets. The Transitive Reciprocated Triplets effect models whether actor $i$ in the network has a tendency towards or against forming a tie that results in structure a) in Figure 3. Thus, when included in a model jointly with the Transitive Triplets effect and the Reciprocity effect, it models whether an actor is differentially likely to reciprocate a tie within, compared to outside of a transitive triplet.

The further structures d) and e) of Figure 3 that combine transitivity and reciprocity include structure a) as a substructure twice. Structures b) and c) in Figure 3 are of less interest to be directly modelled, as they are likely to relate to aspirational friendships from an outsider to a reciprocated pair of friends, or an aspirational friendship from a pair of reciprocated friends to a third party.

The proposed hypotheses are tested in a series of two models. The first model serves as a baseline with a standard model specification for adolescent friendship networks, which includes the three-cycle effect. In the second model, the Transitive Reciprocated Triplets is added. The findings are consistent with Hypothesis 1 if the Transitive Reciprocated Triplets estimate in the second model is negative. Hypothesis 2 is confirmed if the Three Cycle estimate in the second model has decreased substantively.

\subsection{SAOM Meta-Analysis}

Analysing the change of one network over time can show patterns and regularities in the evolution of this network. However, the analysis of a single network has to be considered a case study. To generalize claims about the evolution of a certain type of networks, multiple, comparable networks should be analysed in a multilevel analysis framework. In the study at hand the meta-analysis procedure proposed by Snijders and Baerveldt (2003) is followed to obtain the mean population value of the parameter estimates 


\begin{tabular}{l|l}
$\begin{array}{l}\text { Effect Name and Math- } \\
\text { ematical Formula }\end{array}$ & Effect Description: The tendency... \\
\hline $\begin{array}{l}\text { Outdegree } \\
s_{1}(x)=\sum_{j} x_{i j}\end{array}$ & $\begin{array}{l}\ldots \text { to form and maintain friendships. This } \\
\text { can be viewed as an intercept. }\end{array}$ \\
\hline $\begin{array}{l}\text { Reciprocity } \\
s_{2}(x)=\sum_{j} x_{i j} x_{j i}\end{array}$ & $\ldots$ to reciprocate friendships. \\
\hline $\begin{array}{l}\text { TransitiveTriplets } \\
s_{3}(x)=\sum_{j, h} x_{i j} x_{i h} x_{j h}\end{array}$ & $\begin{array}{l}\ldots \text { to form and maintain ties to friends-of- } \\
\text { friends. }\end{array}$ \\
\hline $\begin{array}{l}\text { Trans.Recip.Triplets } \\
s_{4}(x)=\sum_{j, h} x_{i j} x_{i h} x_{j h} x_{h i}\end{array}$ & $\begin{array}{l}\ldots \text { to have reciprocated ties to friends-of- } \\
\text { friends. }\end{array}$ \\
\hline $\begin{array}{l}\text { ThreeCycles } \\
s_{5}(x)=\sum_{j, h} x_{i j} x_{h i} x_{j h}\end{array}$ & $\begin{array}{l}\ldots \text { to be tied to those who perceive ego as a } \\
\text { friend-of-friend. }\end{array}$ \\
\hline $\begin{array}{l}\text { IndegreePopularity } \\
s_{6}(x)=\sum_{j} x_{i j} x_{+j}\end{array}$ & $\begin{array}{l}\ldots \text { to attach to popular actors in the net- } \\
\text { work. }\end{array}$ \\
\hline $\begin{array}{l}\text { OutdegreePopularity } \\
s_{7}(x)=\sum_{j} x_{i j} x_{j+}\end{array}$ & $\begin{array}{l}\ldots \text { to be tied to those that nominate many } \\
\text { others as friends. }\end{array}$ \\
\hline $\begin{array}{l}\text { IndegreeActivity } \\
s_{8}(x)=\sum_{j} x_{i j} x_{+i}\end{array}$ & $\begin{array}{l}\ldots \text { of popular actors to nominate more } \\
\text { friends. }\end{array}$ \\
\hline $\begin{array}{l}\text { OutdegreeActivity } \\
s_{9}(x)=\sum_{j} x_{i j} x_{i+}\end{array}$ & $\begin{array}{l}\ldots \text { of actors with many outgoing friendships } \\
\text { to nominate more friends. }\end{array}$ \\
\hline $\begin{array}{l}\text { SexAlter } \\
s_{10}(x)=\sum_{j} v_{j} x_{i j}\end{array}$ & $\begin{array}{l}\text { boys. } \\
s_{11}(x)=v_{i} \sum_{j} x_{i j}\end{array}$ \\
\hline $\begin{array}{l}\text { SameSex } \\
s_{12}(x)=\sum_{j} x_{i j} I\left\{v_{i}=v_{j}\right\}\end{array}$ & sex. \\
\hline
\end{tabular}

The used effects $s(x)$ are numbered 1 to 12 . A tie from actor $i$ to actor $j$ is called $x_{i j}$. The variables $x_{+j}$ and $x_{j}$ refer to all incoming and outgoing ties of actor $j$, respectively. Variable $v_{i}$ denotes the sex of actor $i$ where female is coded 1 . The covariate $v_{i}$ is centred. The indicator function $I$ equals 1 if the sender and recipient of a tie are of the same sex and 0 otherwise.

Table 1: Effects included in the analysis 
for each dataset. It is assumed that the different networks from which the parameters are estimated are randomly drawn from a population of networks.

The method uses a two-step approach. In the first step, the identically specified model is estimated for each network. Using these, in the second step, the mean population value for each included effect is estimated using a weighted least squares (WLS) estimator, originally proposed by Cochran (1954). Using this estimator assumes that the parameter estimates and the standard errors of the individual networks are uncorrelated. This assumption is tested in the data analysis.

\subsection{SAOM Goodness of Fit}

As opposed to many other statistical techniques, for network models such as Exponential Random Graph Models (ERGMs) or SAOMs, no single number (such as $R^{2}, A I C$, etc.) has been developed that describes the goodness of fit $(\mathrm{GoF})$ of a model specification. However, testing whether a model is a good representation of data is a crucial part of statistical modelling. Lospinoso (2012) developed a method to assess GoF for SAOMs using auxiliary statistics of networks that are not explicitly modelled, such as degree distributions or the triad census. The approach is similar to the work of Hunter et al. (2008) for ERGMs. It was applied to SAOMs for example by Conaldi et al. (2012).

In this method, the parameters obtained from the estimation are used to simulate a number of networks. The simulated networks are compared to the empirically observed network with regards to the auxiliary statistics. The results of the simulation are visualised using a violin plot (Hintze and Nelson, 1998) with the observed values superimposed. This allows determining whether the proposed model generates networks that are characterised by similar values for various statistics as the observed network. Further, for the auxiliary statistics, a p-value is calculated based on the so-called Mahalanobis distance that allows to conclude whether the current model represents the empirical data well.

The statistic used in the current study is the triad census (Holland and Leinhardt, 1976), as this is directly related to the research questions addressed. The triad census counts the number of occurrences of each potential triadic configuration in a network. The numbers of reciprocated dyads, of transitive triplets, of three cycles, and of all triadic configurations presented in Figure 3 are linear combinations of the triad census. The GOF procedure is applied to each analysed network of the two datasets individually. As this raises issues of multiple testing, the resulting p-values are combined using the Bonferroni method for either dataset to test whether the proposed 
Model 1

Model 2

\begin{tabular}{lcccccc} 
& estimate & & s.e. & estimate & & s.e. \\
\hline Outdegree & -2.60 & $* * *$ & 0.13 & -2.63 & $* * *$ & 0.14 \\
Reciprocity & 2.60 & $* * *$ & 0.13 & 2.79 & $* * *$ & 0.094 \\
& & & & & & \\
Transitive Triplets & 0.94 & $* * *$ & 0.071 & 1.06 & $* * *$ & 0.067 \\
3-Cycles & -0.41 & $* *$ & 0.13 & 0.21 & & 0.14 \\
Trans. Rec. Triplets & & & & -0.79 & $* * *$ & 0.082 \\
& & & & & & \\
Indegree - Popularity & 0.020 & & 0.022 & 0.006 & & 0.028 \\
Outdegree - Popularity & -0.26 & $* * *$ & 0.047 & -0.27 & $* * *$ & 0.056 \\
& & & & & & \\
Sex Alter & -0.43 & $* * *$ & 0.068 & -0.45 & $* * *$ & 0.074 \\
Sex Ego & 0.21 & & 0.11 & 0.21 & & 0.11 \\
Same Sex & 0.55 & $* * *$ & 0.087 & 0.54 & $* * *$ & 0.082 \\
\hline p-values: $* * *<0.001 ; * *<0.01 ;$ df: 17 & & & & &
\end{tabular}

Table 2: Results of the Meta-Analysis Dutch Data

model specification is rejected.

\section{Results}

\subsection{Parameter Estimates}

The results of the Siena meta-analyses are displayed in Table 2 for the Dutch data and Table 3 for the British data. The parameter estimates of interest in both analyses for the hypothesis are the Three Cycle effect in model 1 and the Three Cycle and Transitive Reciprocated Triplets effect in model 2. While in the first model the Three Cycle parameter is negative, significant and of substantive size in both meta-analyses, in the second model the parameter is estimated positive and non-significant in both analyses. The Transitive Reciprocated Triplets estimate additionally included in the second model is estimated significantly negative and of twice the size as the previously modelled Three Cycle effect in each dataset. This suggests that the negative Three Cycle estimate in model 1 is spurious.

In both analyses, not including the Transitive Reciprocated Triplets effect leads to a bias in the estimate of the Reciprocity and Transitive Triplets effect. Both parameters are estimated lower in the first model compared to the second one. This is not surprising, as the negatively estimated Transitive 
Model 1

Model 2

\begin{tabular}{lcccccc} 
& estimate & & s.e. & estimate & s.e. \\
\hline Outdegree & -2.57 & $* * *$ & 0.11 & -2.76 & $* * *$ & 0.11 \\
Reciprocity & 2.24 & $* * *$ & 0.076 & 2.61 & $* * *$ & 0.06 \\
& & & & & & \\
Transitive Triplets & 0.69 & $* * *$ & 0.027 & 0.83 & $* * *$ & 0.025 \\
3-Cycles & -0.44 & $* * *$ & 0.039 & 0.056 & & 0.045 \\
Trans. Rec. Triplets & & & & -0.60 & $* * *$ & 0.031 \\
& & & & & & \\
Indegree - Popularity & -0.013 & $* *$ & 0.004 & -0.007 & & 0.004 \\
Indegree - Activity & -0.16 & $* * *$ & 0.019 & -0.16 & $* * *$ & 0.018 \\
Outdegree - Activity & 0.027 & & 0.015 & 0.036 & & 0.018 \\
& & & & & & \\
Sex Alter & 0.072 & & 0.036 & 0.069 & & 0.036 \\
Sex Ego & 0.009 & & 0.039 & -0.011 & & 0.040 \\
Same Sex & 0.66 & $* * *$ & 0.067 & 0.57 & $* * *$ & 0.063 \\
\hline p-values: $* * *<0.001 ; * *<0.01 ;$ df: 10 & & & &
\end{tabular}

Table 3: Results of the Meta-Analysis British Data

Reciprocated Triplets effect models the interaction between the two former effects. Omission of a negative interaction effect can often be associated with the main effects being estimated too low.

As the interpretation of the results of the two models is qualitatively similar for most effects, I discuss these parameters without distinguishing between the data-sets. For both datasets, the negative Outdegree parameter can be understood as an intercept with the interpretation that friendships are relatively sparse, as already seen in the description of the networks. However, mirroring the description of the data, ties are more likely to exist if they are reciprocated, embedded in a transitive triplet or between same sex pupil.

In the Dutch data, girls are less likely to be nominated as friends, seen in the negative Sex Alter parameter. This tendency cannot be observed in the British data. Further, in the Dutch data, pupils that send a lot of ties are less likely to be nominated as friends, represented by the negative Outdegree Popularity parameter. The British data shows a small, and in model 1 significant, tendency against preferential attachment (Indegree Popularity). Additionally, adolescents that receive many nominations are less likely to nominate others as friends (Indegree Activity), ceteris paribus. Both tendencies are not modelled in the Dutch data.

The differences between the results of the two datasets can be attributed 
to the different contexts or the different method of collecting the data and, for the degree related effects, to the different model specification. However, the main determinants of friendship evolution are similar in the two networks (reciprocity, transitivity, and sex homophily), especially concerning the parameter estimates relating to the tested hypotheses (three cycles and transitive reciprocated triplets).

The assumption that parameter estimates and standard errors are uncorrelated underlying the WLS estimator is violated in some cases. In the Dutch data, the Reciprocity, Transitive Triplets, and Indegree Popularity estimates in both models, as well as Three Cycles estimate in the first model show a p-value $<0.05$ in a two-sided test. This means that these parameter estimates are likely to be biased. However, given the consistency of directionality and significance of the parameter estimates in each analysed network, the bias likely relates to the exact size of the parameter, not to direction or significance. Further, and most importantly, the parameter estimates and standard errors for Three Cycles and Transitive Reciprocated Triplets in the second model are uncorrelated. This means the parameter estimates most relevant to hypotheses testing are unbiased. In the British data, the parameter estimates and standard errors are uncorrelated in both models for all parameters. This means that all estimates are unbiased by the estimator.

\subsection{Goodness of Fit}

Figure $4 \mathrm{a}$ and Figure $4 \mathrm{~b}$ show examples of GOF plots for the first network of the British data using the two separate models. The violin plots show the expected number of the different configurations in the triad census based on 1000 simulations of networks under the respectively proposed model. The superimposed points show the empirically observed number of the respective configuration. Figure 4 a shows that for model 1 especially the triadic configurations with one asymmetric and two reciprocated ties fit poorly (configurations $120 \mathrm{U}, 120 \mathrm{C}$, and 210 ). This is indicated by the observed values (red dots) lying outside the confidence intervals of simulated networks (dotted lines). The overall $\mathrm{p}$-value is $<0.001$, i.e. the proposed model cannot reproduce the observed network well with regards to the triad census. Model 1 does not appropriately model decisions of actors which ties to form and keep embedded in triadic configurations. Figure $4 \mathrm{~b}$ shows that the second model fits the empirical data better with a p-value of 0.26 , which is considerably higher than the usual significance threshold of 0.05 (p-values taken from Table 4). This suggests that the second model fits the empirical data well.

Table 4 shows the p-values for the GOF test for each of the analysed 


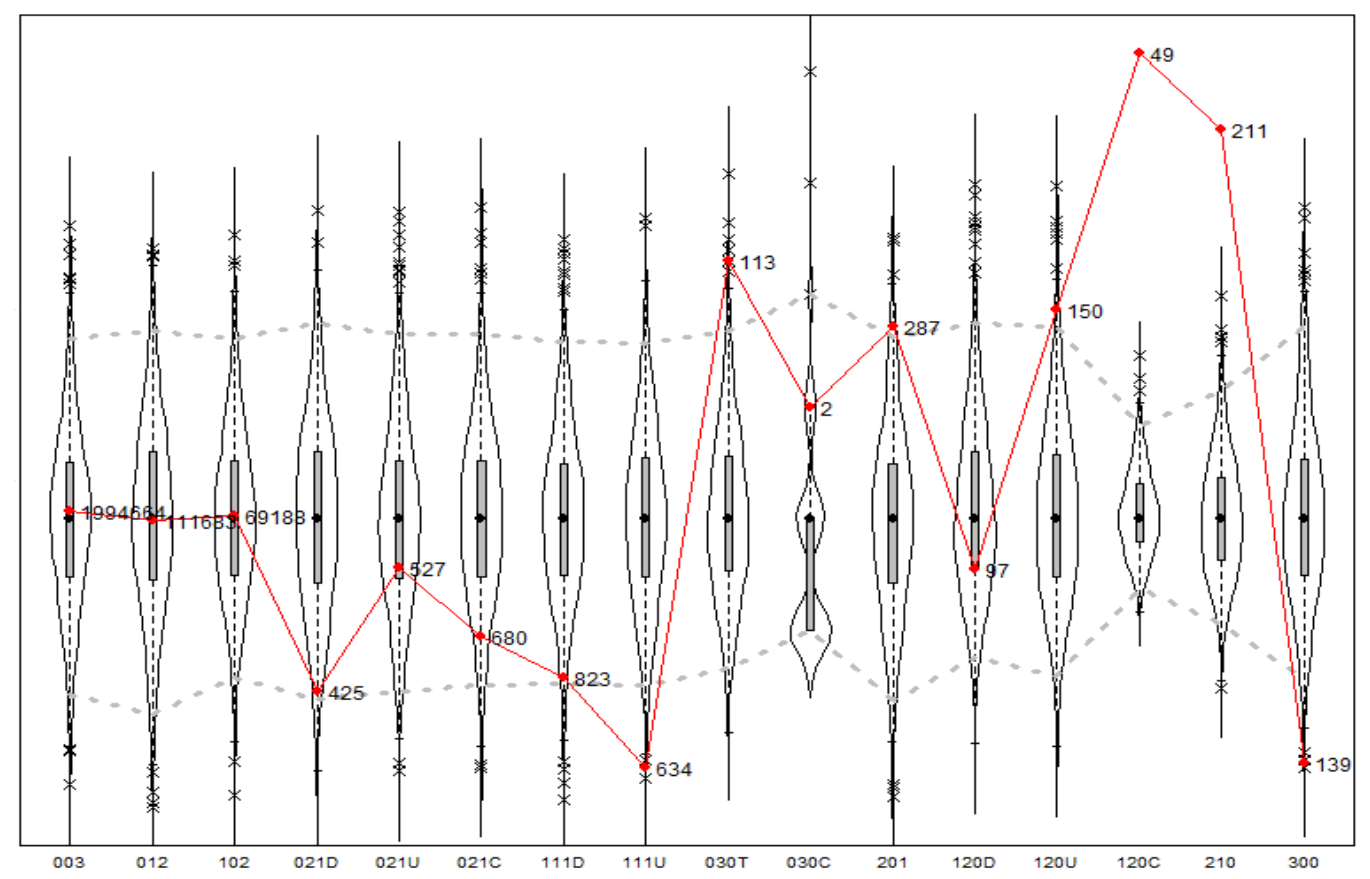

(a) Model 1

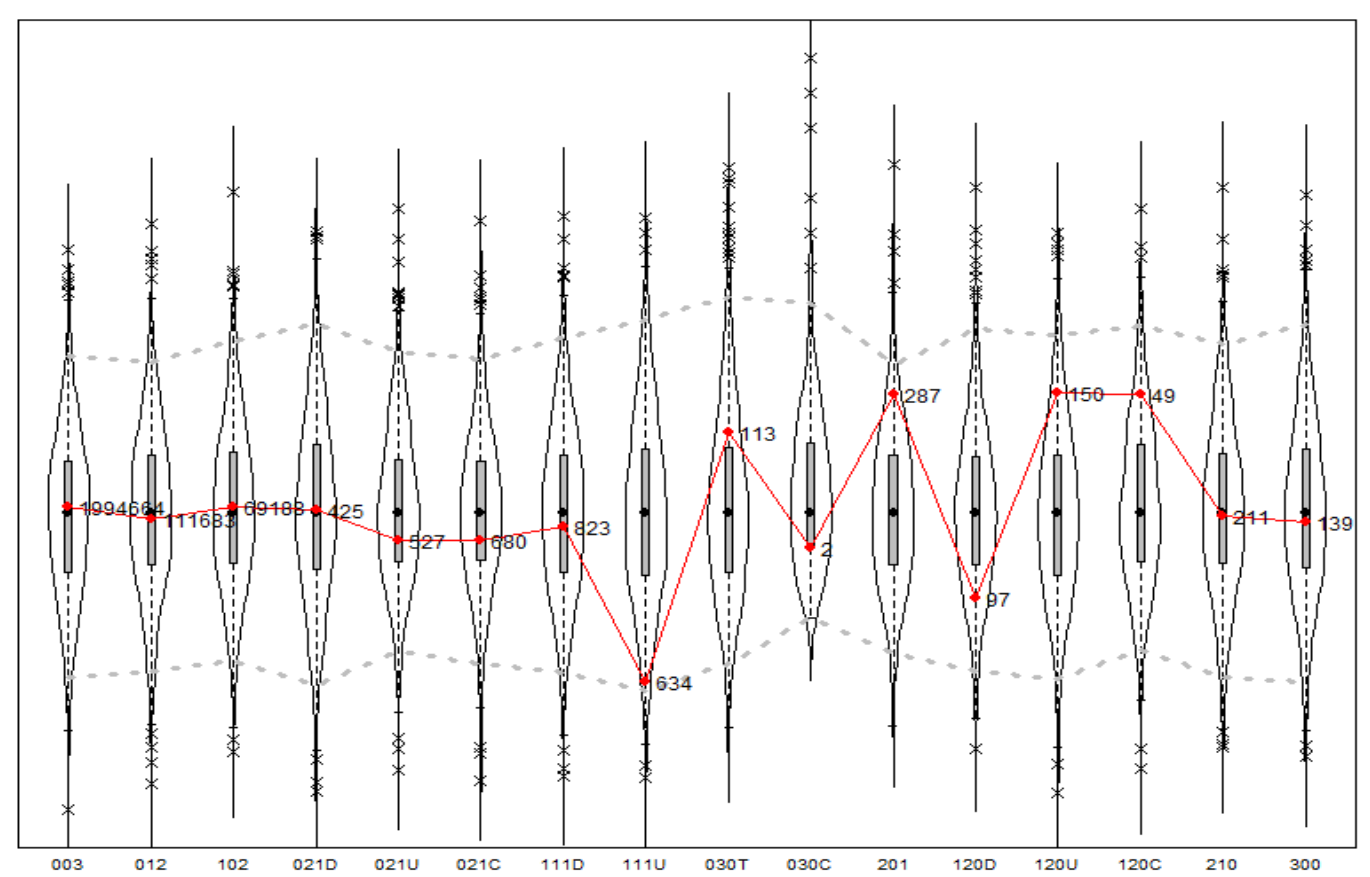

(b) Model 2

Figure 4: GOF plots of Triad Census for School 1, British Data 


\begin{tabular}{|c|c|c|c|c|}
\hline \multicolumn{2}{|c|}{ Dutch data } & \multirow{2}{*}{$\begin{array}{c}\text { Network } \\
\text { Nr. }\end{array}$} & \multicolumn{2}{|c|}{ British data } \\
\hline Model 1 & Model 2 & & Model 1 & Model 2 \\
\hline 0.003 立 & 0.519 & 1 & $<0.001$ 々々之 & 0.260 \\
\hline 0.136 & 0.389 & 2 & $<0.001$ 文々 & 之 0.049 \\
\hline 0.258 & 0.261 & 3 & $<0.001$ 文々之 & 0.972 \\
\hline 0.047 々 & 0.499 & 4 & $<0.001$ 文文 & 让 0.004 \\
\hline$<0.001$ 々々々 & 0.101 & 5 & $<0.001$ 々文々 & 立足 0.001 \\
\hline 0.004 立立 & z 0.013 & 6 & $<0.001$ 文々 & 0.220 \\
\hline 0.006 立文 & 议 0.005 & 7 & $<0.001$ 文々 & \& 0.014 \\
\hline 0.415 & 0.935 & 8 & $<0.001$ 々々之 & 计 0.003 \\
\hline 0.500 & 0.594 & 9 & $<0.001$ 文々之 & 0.089 \\
\hline exclu & & 10 & $<0.001$ 文々 & 0.364 \\
\hline 0.001 立 & 々 0.027 & 11 & $<0.001$ 文々 & 0.455 \\
\hline 0.061 & 0.084 & 12 & & \\
\hline 0.111 & 0.103 & 13 & & \\
\hline 0.007 之立 & 0.146 & 14 & & \\
\hline 0.310 & 0.325 & 15 & & \\
\hline 0.462 & 0.397 & 16 & & \\
\hline 0.651 & 0.922 & 17 & & \\
\hline 0.082 & 0.273 & 18 & & \\
\hline 0.005 文文 & 0.067 & 19 & & \\
\hline
\end{tabular}

Good fit if p-value $>0.05$; poor fit indicated by p-values: $\{<0.05$; 立文 $<0.01 ;$ 立立 $<0.001$.

Table 4: p-values for GOF triad census all analysed Networks

networks in both datasets, indicating whether the model specifications fit the respective data well with regards to the triad census. For the Dutch data on the left-hand side of the table, in all but two cases (network 7 and network 13), model 2 outperforms model 1 in terms of GOF. Using the conservative Bonferroni correction for multiple testing of the same hypothesis, in order for a model to be rejected one of the p-values should be smaller than $\alpha / n$, where $\alpha$ is the significance level ( 0.05 by convention) and $n$ is the number of test, 18 in this case. This results in model rejection if a p-value $<0.003$. For the first model, two p-values are $<0.003$ (networks 5 and 11), which means that the hypothesis that model 1 provides good fit is rejected. The hypothesis that the second model fits the data well is not rejected, as the lowest obtained p-value $=0.005$ (network 7 ).

On the right-hand side of Table 4 the p-values of the GOF tests for the British data are displayed. Model 2 systematically exhibits a better fit than model 1. Using the Bonferroni correction, a model specification is rejected if 
$\mathrm{p}<0.005$. Consequently, the model specification does not fit networks 4,5 , and 8 well. However, finding one model specification that results in a good fit for all networks was not possible with the effects that are usually included in SAOM analyses. The presented model was the most parsimonious that provided good fit for most networks and for which no network had a p-value $<0.001$; therefore, this model specification was deemed satisfying for the purpose of this article.

\section{Summary, Discussion and Conclusion}

The present study analysed the relationship between reciprocity and transitivity in friendship networks. Although reciprocity and transitivity have been extensively studied by themselves, their relationship to one another has not been systematically analysed using statistical network analysis techniques. Using a perspective that focuses on the likelihood of interpersonal interaction and rewards to a friendship, I hypothesised that the statistical interaction is negative. In a statistical model of friendship evolution, this is represented by a tendency against reciprocation within transitive triplets. Further, I hypothesised that the often observed tendency against forming three cycles in friendship networks might be spurious and will be substantially reduced when controlling for the tendency against reciprocation in transitive triads. The hypotheses were tested using SAOM meta-analyses of two datasets of friendship networks from different contexts.

Hypothesis 1 is confirmed. The tendency towards reciprocation within transitive triplets is lower than outside of transitive triplets in each context. The other, complementary interpretation of the same parameter is that once a potential tie is reciprocated, embeddedness in a transitive triad does not make the tie more likely to exist.

Hypothesis 2 is confirmed, too. After controlling for the tendency to reciprocate ties within transitive triplets, no tendency against forming threecycles is found. This suggests that the negative three-cycle parameter, which is persistently found in analyses of friendship networks using SAOMs, is spurious and a result of a misspecified model.

Further, GOF testing of the two different models shows that including the tendency against reciprocation in transitive groups results in improved fit. With the new model specification, the fit of the model to 26 out of 29 networks was satisfying. 


\subsection{Discussion of Results}

The first main finding of the study at hand - embedding in a transitive group is more important for a one-sided tie than a reciprocal one - is in line with well-established theories in social network science. Both the sociological perspective that focuses on friends spending time together (Davis, 1963; Feld, 1981) and the psychological approach (Heider, 1958) can explain why friendships in triads are more stable than outside of them. While both approaches in principle are designed and formulated in such a way that they explain why transitive embedding leads to reciprocated friendships, either can equally be applied to one-sided friendships.

According to the former, spending time together is a condition for friendships. However, it is a necessary but not sufficient condition for friendships. Thus, even a one-sided tie fulfils this condition if a forum for interaction, such as a social group, exists. Equally, balance theory and social exchange theory can be used to explain why one-sided friendships are stabilised in transitive triads. As Carley and Krackhardt (1996) put it:

Heider's formulation of inconsistency is not based on actual balance, but rather on people's perceptions of reciprocated liking, i.e. on non-symmetry. (...) balance exists if Person 1 thinks that Person 1 likes Person 2 and Person 1 thinks that Person 2 likes Person 1. (p. 4)

Thus, in the absence of mutual liking, a social group still provides a framework in which a one-sided friendship can exist. The group provides a rationale for Person 2 to be nice to Person 1, which leads to Person 1's perception of mutual liking.

The finding that reciprocity and transitivity interact negatively is supported by some studies (e.g. Igarashi, 2012; Lospinoso, 2012; Snijders and Steglich, 2014); however, these studies mainly include an effect that models reciprocity in transitive triads to improve the fit of their respective models and do not engage in a discussion of what these results mean.

The second finding of this article is that the tendency against forming threecycles is spurious. This finding is more controversial, as it suggests that many past studies incorrectly interpreted the negative three-cycle parameter as an indicator of hierarchy in one-sided friendships. Do the findings of this article show that friendships are hierarchy-free, even if they are one-sided? Good arguments can be found for either position.

On the one hand, it is plausible that one-sided friendships lead to a powerdifference between the sender and recipient of a friendship. The recipient can 
threaten the sender to withdraw, or promise to give approval to the sender under certain conditions, thus creating a clear hierarchy. Hallinan (1978) argues from a process-based perspective that a friendship offer, i.e. the first step to a friendships generally comes from a lower-status to a higher-status individual. Dijkstra et al. (2010) give an explanation why adolescents would strive for such asymmetric friendships, even though it implies a power imbalance. They argue and show empirically that being friends, even one-sided, with high-status individuals results in a higher status for oneself. They call this "basking in reflected glory". A further empirical study that explicitly models hierarchy difference between friends is carried out by Ball and Newman (2013). They find that they can infer a status ranking system from one-sided friendship nominations and that this ranking correlates closely with other status-related characteristics of the participants, such as age and overall popularity. Thus, a wide array of work that does not base its finding on the negative three-cycle come to the same conclusion that one-sided friendships have a hierarchy imbalance.

On the other hand, many studies pose the exact opposite. If there is a clear hierarchy difference in a friendship, it tends to be of low quality, therefore unsatisfying and will most likely be terminated (Veniegas and Peplau, 1997). Additionally, high status adolescents tend to be mean to keep their high status position and are consequently less popular (Adler and Adler, 1995). Thus, one-sided friendships from low-status to high-status individuals are unlikely to exist in large numbers. Given the high proportion of one-sided friendships observed in empirical data (see Tables A.1 and A.2), in light of these elaborations it is improbable that all of them exist between adolescents of different hierarchy levels. Additionally, some work defines friendships as generally hierarchy-free, i.e. a relationship between equals (e.g. Allan, 1986). Finally, even the Article by Ball and Newman (2013) notes that under the proposed ranking model, most one-sided friendships are between individuals of equal status.

In light of the findings of this study and the literature on whether a onesided friendship indicates a hierarchy-difference, a careful conclusion is that although some one-sided friendships might reflect a difference in hierarchy, it can hardly be stated a universal feature of them. Thus, if a sufficiently large proportion of one-sided friendships is non-hierarchical, then no tendency against three-cycle should be observed, as this requires all involved ties to reflect hierarchy on the same dimension.

Finally, if a one-sided friendship cannot be universally interpreted as an aspirational friendship from a lower to a higher ranking adolescent, what can be inferred from the information that a friendship is one-sided? One possibility 
is that these friendships are only one-sided in the observed data due to a differential understanding of the term "friendship" by different participants, echoing Fischer (1982). In other words, some individuals might have a lower threshold of intimacy for designating other as friends, thus, a perfectly symmetric relationship could be called a friendship by only of the involved parties, resulting in observing an asymmetric friendship. Asymmetry of friendships would then only be a feature of the data, but not reflecting asymmetry of relations in the real world. This leads back to the basic idea (see Section 1.1) that friendship is by definition mutual, otherwise it cannot be called a friendship:

Wanting to be friends does not make you friends any more than wanting to be healthy makes you healthy. (Aristotle, Eudemian Ethics, in Annas, 1977)

Future research could focus on this broad question what can be inferred from observing a one-sided friendship.

Further research is needed to understand whether this pattern is specific to friendships among adolescents. Compared to adolescent friendship networks, the structure of adult friendship networks has been less studied. Therefore, it would be interesting to apply the same question to an adult population using appropriate data and methodology.

While this study focuses on friendship, both in the theoretical elaboration and empirical analysis, it would be interesting to see whether other positive networks exhibit a similar tendency against reciprocation in transitive groups. Other network types in which transitivity and reciprocity are equally important analyse for example advice (Agneessens and Wittek, 2012), defending (Huitsing et al., 2014), hanging about (Molano et al., 2013), or leadership (Emery et al., 2011) networks. Consequently, the question arises whether the results from this study generalise to other positive networks.

Finally, the proposed hypotheses could equally be applied to the interaction between reciprocity and other group-based mechanisms, especially homophily. Similar to transitivity, homophily leads to individuals spending time together in group-based situations (Feld, 1982). Thus, further research could establish whether the interaction between reciprocity and homophily is negative, too.

\subsection{Conclusion}

The study at hand suggests that the reduced tendency towards reciprocation within transitive triplets is a crucial part of the evolution of friendship networks. The Three Cycle effect that was commonly used in previous studies 
using statistical methods for network dynamics and seen as an indication for the presence of local hierarchies has been shown to be spurious in two large data-sets that are typical data for adolescent friendship networks. Future studies on complete friendship networks should consider omitting three cycles from network models and focus on the tendency against reciprocation in transitive triplets instead.

\section{References}

Adler, P. and Adler, P. (1995). Dynamics of inclusion and exclusion in preadolescent cliques. Social Psychology Quarterly, 58(3):145-162.

Agneessens, F. and Wittek, R. (2012). Where do intra-organizational advice relations come from? The role of informal status and social capital in social exchange. Social Networks, 34(3):333-345.

Allan, G. (1986). Friendship and Care for Elderly People. Ageing and Society, $6(01): 1-12$.

Annas, J. (1977). Plato and Aristotle on Friendship and Altruism. Mind, 86(344):532-554.

Baerveldt, C., Weerm, F., Van Rossem, R., Verman de, M., Weerman, F. M., and Vermande, M. (2004). Student's Delinquency and Correlates with Strong and Weaker Ties: A Study of Students' Networks in Dutch High Schools. Connections, 26:11-28.

Ball, B. and Newman, M. (2013). Friendship networks and social status. Network Science, 1(1):16-30.

Carley, K. M. and Krackhardt, D. (1996). Cognitive inconsistencies and non-symmetric friendship. Social Networks, 18(1):1-27.

Cheadle, J. E., Stevens, M., Williams, D. T., and Goosby, B. J. (2013). The differential contributions of teen drinking homophily to new and existing friendships: An empirical assessment of assortative and proximity selection mechanisms. Social science research, 42(5):1297-310.

Cochran, W. G. (1954). The Combination of Estimates from Different Experiments. Biometrics, 10(1):101-129.

Conaldi, G., Lomi, A., and Tonellato, M. (2012). Dynamic Models of Affiliation and the Network Structure of Problem Solving in an Open Source Software Project. Organizational Research Methods, 15(3):385-412. 
Davis, J. A. (1963). Structural Balance, Mechanical Solidarity, and Interpersonal Relations. American Journal of Sociology, 68(4):444-462.

Davis, J. A. (1970). Clustering and Hierarchy in Interpersonal Relations : Testing Two Graph Theoretical Models on 742 Sociomatrices. American Journal of Sociology, 35(5):843-851.

Davis, J. A. and Leinhardt, S. (1970). The structure of positive interpersonal relations in small groups. In Berger, J., Zelditch, M., and Anderson, B., editors, Sociological Theories in Progress. Houghton Mifflin, Boston.

Dijkstra, J. K., Cillessen, A. H. N., Lindenberg, S., and Veenstra, R. (2010). Basking in Reflected Glory and Its Limits: Why Adolescents Hang Out With Popular Peers. Journal of Research on Adolescence, 20(4):942-958.

Ellwardt, L., Steglich, C., and Wittek, R. (2012). The co-evolution of gossip and friendship in workplace social networks. Social Networks, 34(4):623633.

Emerson, R. M. (1976). Social Exchange Theory. Annual Review of Sociology, $2: 335-362$.

Emery, C., Daniloski, K., and Hamby, a. (2011). The Reciprocal Effects of Self-View as a Leader and Leadership Emergence. Small Group Research, 42(2):199-224.

Feld, S. L. (1981). The Focused Organization of Social Ties. American Journal of Sociology, 86(5):1015-1035.

Feld, S. L. (1982). Social Structural Determinants of Similarity among Associates. American Sociological Review, 47(6):797-801.

Fischer, C. S. (1982). What do we mean by 'friend'? an inductive study. Social Networks, 3(4):287-306.

Giletta, M., Scholte, R. H. J., Prinstein, M. J., Engels, R. C. M. E., Rabaglietti, E., and Burk, W. J. (2012). Friendship context matters: examining the domain specificity of alcohol and depression socialization among adolescents. Journal of abnormal child psychology, 40(7):1027-43.

Goodreau, S. M., Kitts, J. A., and Morris, M. (2009). Birds of Feather, or Friend of a friend? Using Exponential Random Graph Models to Investigate Adolescent Social Networks. Demography, 46(1):103-125. 
Granovetter, M. S. (1973). The Strength of Weak Ties'. American Journal of Sociology, 78(6):1360-1380.

Granovetter, M. S. (1985). Economic action and social structure: the problem of embeddeness. American Journal of Sociology, 91(3):481-510.

Hallinan, M. T. (1978). The Process of Friendship Formation. Social Networks, 1:193-210.

Heider, F. (1946). Attitudes and cognitive organization. The Journal of psychology, 21:107-112.

Heider, F. (1958). The Psychology of Interpersonal Relations. Wiley, New York.

Heidler, R., Gamper, M., Herz, A., and Eß er, F. (2014). Relationship patterns in the 19th century: The friendship network in a German boys' school class from 1880 to 1881 revisited. Social Networks, 37:1-13.

Hintze, J. and Nelson, R. (1998). Violin plots: a box plot-density trace synergism. The American Statistician, 52(2):181-184.

Holland, P. W. and Leinhardt, S. (1976). Local Structures in Social Networks. Sociological Methodology, 7:1-45.

Homans, G. (1950). The human Group. Harcourt, Brace \& World, New York.

Houtzager, B. and Baerveldt, C. (1999). Just like normal: A social network study of the relation between petty crime and the intimacy of adolescent friendships. Social Behavior and Personality, 27(2):177-192.

Huitsing, G., Snijders, T. A. B., Van Duijn, M. A. J., and Veenstra, R. (2014). Victims, bullies, and their defenders: a longitudinal study of the coevolution of positive and negative networks. Development and Psychopathology, 26(3):645-59.

Hunter, D. R., Goodreau, S. M., and Handcock, M. S. (2008). Goodness of Fit of Social Network Models. Journal of the American Statistical Association, 103(481):248-258.

Igarashi, T. (2012). Longitudinal changes in face-to-face and text messagemediated friendship networks. In Lusher, D., Koskinen, J., and Robins, G., editors, Exponential random graph models for social networks: Theories, methods and applications, pages 248-259. Cambridge University Press, Cambridge. 
Krackhardt, D. (1992). The Strength of Strong Ties: The Importance of Philos in Organizations. In Nohria, N. and Eccles, R., editors, Networks and organizations : structure, form, and action, pages 216-239. Harvard Business School Press, Boston.

Krackhardt, D. (1998). Simmelian ties: Super strong and sticky. In Kramer, R. and Neale, M., editors, Power and influence in organizations, pages 21-38. Sage, Thousand Oaks.

Krackhardt, D. (1999). The Ties that Torture: Simmelian Tie Analysis in Organizations. Research in the Sociology of Organizations, 16:183-210.

Lazarsfeld, P. F. and Merton, R. K. (1954). Friendship as a social process. In Berger, M., Abel, T., and Page, C. S., editors, Freedom and Control in Modern Society, volume 18, pages 18-66. Van Nostrand, New York.

Liljeros, F., Edling, C. R., Amaral, L. A., Stanley, H. E., and Aberg, Y. (2001). The web of human sexual contacts. Nature, 411:907-908.

Lospinoso, J. A. (2012). Statistical Methods for Social Network Dynamics. DPhil Thesis, University of Oxford, Oxford.

Merton, R. K. (1968). The Matthew Effect in Science. Science, 159:56-63.

Molano, A., Jones, S. M., Brown, J. L., and Aber, J. L. (2013). Selection and Socialization of Aggressive and Prosocial Behavior: The Moderating Role of Social-Cognitive Processes. Journal of Research on Adolescence, 23(3):424-436.

Newcomb, T. M. (1956). The prediction of interpersonal attraction. American Psychologist, 11:575-586.

Newcomb, T. M. (1961). The Acquaintance Process. Holt, Rinehart ans Winston, New York.

Preciado, P., Snijders, T. A. B., Burk, W. J., Stattin, H., and Kerr, M. (2012). Does proximity matter? Distance dependence of adolescent friendships. Social Networks, 34(1):1-14.

Ripley, R. M., Snijders, T. A. B., Boda, Z., Vörös, A., and Preciado, P. (2013). Manual for RSiena. University of Oxford, Department of Statistics; Nuffield College, Oxford. 
Rivera, M. T., Soderstrom, S. B., and Uzzi, B. (2010). Dynamics of Dyads in Social Networks: Assortative, Relational, and Proximity Mechanisms. Annual Review of Sociology, 36(1):91-115.

Rusbult, C. E. and Buunk, B. P. (1993). Commitment Processes in Close Relationships: An Interdependence Analysis. Journal of Social and Personal Relationships, 10(2):175-204.

Schaefer, D. R., Light, J. M., Fabes, R. A., Hanish, L. D., and Martin, C. L. (2010). Fundamental Principles of Network Formation among Preschool Children. Social Networks, 32(1):61-71.

Simmel, G. (1950). The Sociology of Georg Simmel. Free press, New York.

Snijders, T. A. B. (2001). The Statistical Evaluation of Social Network Dynamics. Sociological Methodology, 31(1):1-33.

Snijders, T. A. B. (2005). Models for Longitudinal Network Data. In Carrington, P., Scott, J., and Wasserman, S., editors, Models and methods in social network analysis, pages 215-247. Cambridge University Press, New York.

Snijders, T. A. B. (2011). Statistical Models for Social Networks. Annual Review of Sociology, 37(1):131-153.

Snijders, T. A. B. and Baerveldt, C. (2003). A multilevel network study of the effects of delinquent behavior on friendship evolution. Journal of Mathmatical Sociology, 27(2-3):123-151.

Snijders, T. A. B. and Steglich, C. E. G. (2014). Representing Micro-Macro Linkages by Actor-based Dynamic Network Models. Sociological Methods \& Research.

Snijders, T. A. B., van de Bunt, G. G., and Steglich, C. E. (2010). Introduction to stochastic actor-based models for network dynamics. Social Networks, 32(1):44-60.

Steglich, C., Sinclair, P., Holliday, J., and Moore, L. (2012). Actor-based analysis of peer influence in A Stop Smoking In Schools Trial (ASSIST). Social Networks, 34(3):359-369.

Tortoriello, M. and Krackhardt, D. (2010). Activating cross-boundary knowledge: the role of Simmelian ties in the generation of innovations. Academy of Management Journal, 53(1):167-181. 
van de Bunt, G. G., Van Duijn, M. A., and Snijders, T. A. B. (1999). Friendship Networks Through Time: An Actor-Oriented Dynamic Statistical Network Model. Computational \& Mathematical Organization Theory, 5(2):167-192.

van Workum, N., Scholte, R. H. J., Cillessen, A. H. N., Lodder, G. M. A., and Giletta, M. (2013). Selection, Deselection, and Socialization Processes of Happiness in Adolescent Friendship Networks. Journal of Research on Adolescence, 23:563-573.

Veenstra, R., Dijkstra, J. K., Steglich, C., and Van Zalk, M. H. W. (2013). Network-Behavior Dynamics. Journal of Research on Adolescence, 23(3):399-412.

Veniegas, R. C. and Peplau, L. A. (1997). Power and the Quality of Same-Sex Friendships. Psychology of Women Quarterly, 21:279-297. 


\section{A Descriptive Statistics}

\begin{tabular}{rcccccccc} 
& & \multicolumn{1}{c}{ Av. Degree } & Jaccard & \multicolumn{3}{c}{ \% Friendships at $t_{2}$} \\
Nr. & $\mathrm{N}$ & \% Male & $t_{1}$ & $t_{2}$ & $t_{1}-t_{2}$ & s. sex & recip. & trans. \\
\hline 1 & 45 & 44 & 2.31 & 3.16 & 0.35 & 70 & 61 & 78 \\
2 & 37 & 46 & 1.05 & 1.86 & 0.24 & 93 & 58 & 68 \\
3 & 33 & 48 & 1.36 & 1.09 & 0.38 & 81 & 56 & 53 \\
4 & 36 & 67 & 1.67 & 2.44 & 0.28 & 74 & 50 & 77 \\
5 & 54 & 37 & 2.24 & 2.85 & 0.38 & 91 & 56 & 72 \\
6 & 91 & 54 & 1.95 & 2.22 & 0.24 & 80 & 41 & 54 \\
7 & 47 & 38 & 2.09 & 2.52 & 0.27 & 85 & 56 & 63 \\
8 & 31 & 48 & 1.68 & 2.52 & 0.24 & 60 & 47 & 77 \\
9 & 82 & 48 & 1.26 & 1.82 & 0.33 & 79 & 51 & 64 \\
10 & 31 & 65 & 0.81 & 1.26 & 0.13 & 37 & 58 & 49 \\
11 & 90 & 53 & 1.91 & 3.40 & 0.26 & 89 & 57 & 80 \\
12 & 61 & 57 & 1.36 & 1.97 & 0.30 & 77 & 53 & 48 \\
13 & 45 & 47 & 1.29 & 1.56 & 0.24 & 73 & 66 & 61 \\
14 & 38 & 50 & 1.61 & 1.37 & 0.28 & 94 & 42 & 44 \\
15 & 43 & 56 & 2.07 & 2.51 & 0.31 & 85 & 52 & 69 \\
16 & 48 & 63 & 1.08 & 1.29 & 0.35 & 77 & 43 & 56 \\
17 & 53 & 51 & 1.43 & 2.23 & 0.32 & 82 & 59 & 64 \\
18 & 52 & 54 & 1.69 & 2.21 & 0.28 & 76 & 53 & 60 \\
19 & 73 & 53 & 1.77 & 2.27 & 0.29 & 84 & 61 & 75 \\
\hline
\end{tabular}

Nr.: classroom number; N: Number of pupil; Jaccard: Jaccard index denoting network change between two time points; s. sex: between same sex peers; recip.: reciprocated; trans.: embedded in a transitive triplet; Classroom 10 excluded from the analysis due to low Jaccard index..

Table A.1: Descriptive Statistics of Dutch Data 


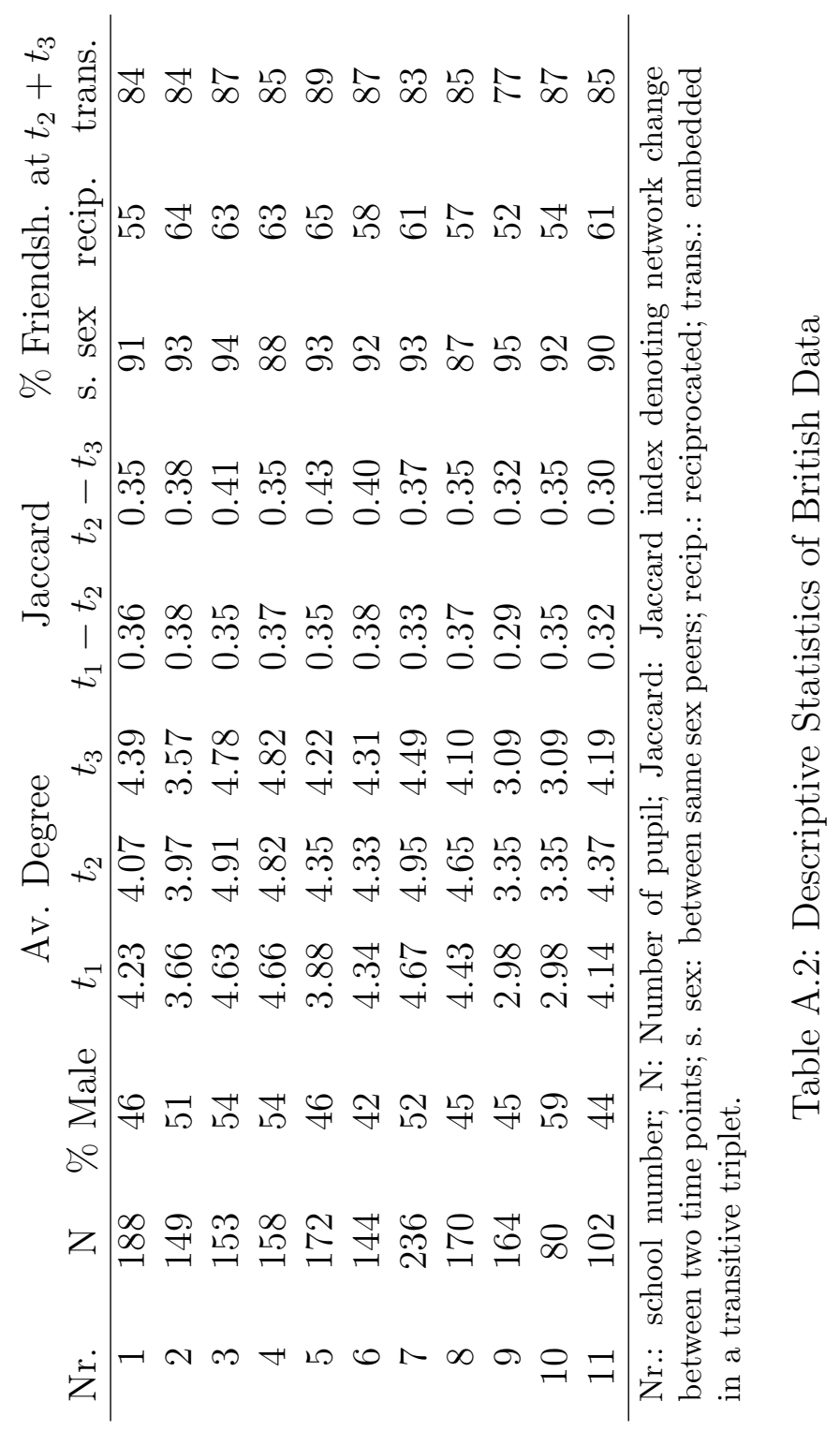

